\title{
Análise comparativa do desenho normativo de instituições reguladoras do presente e do passado*
}

\author{
Antonio Gelis Filho**
}

S U MÁRIO: 1. Introdução; 2. Referencial teórico; 3. Metodologia; 4. Resultados e discussão; 5. Limitações do estudo; 6. Considerações finais.

SUMMARY: 1. Introduction; 2. Theoretical framework; 3. Methodology; 4. Results and discussion; 5. Study limitations; 6. Final remarks.

PAlavras-CHAVE : regulação; instituições reguladoras; desenho normativo; transparência.

KEY WORDS: regulation; regulatory institutions; normative design; transparency.

Este artigo desenvolve um modelo matricial para avaliação do desenho normativo de instituições reguladoras do presente e do passado (autarquias econômicas da república "populista"). Desenho normativo é definido como o conjunto de possibilidades de estruturação e de atuação de uma instituição que é delimitado pelas normas jurídicas que a criaram. O modelo é estruturado a partir de dois parâmetros principais: independência em relação ao poder central e transparência em relação à sociedade. Foram testadas cinco hipóteses, concluindo-se que as instituições reguladoras do presente apresentam desenhos normativos heterogêneos e que se distinguem de instituições do passado tanto por maior independência quanto por maior transparência, sendo a diferença mais acentuada em relação ao segundo parâmetro.

\footnotetext{
* Artigo recebido em fev. e aceito em maio 2006.

** Doutor em administração de empresas pela Eaesp/FGV e professor na mesma instituição; Endereço: Fundação Getulio Vargas — Eaesp — Rua Itapeva, 474, 11º andar — CEP 01332-000, São Paulo, SP, Brasil. E-mail: gelis@fgvsp.br.
} 


\begin{abstract}
Comparative analysis of the normative design of former and current regulatory institutions

This article develops a matrix model to assess the normative design of past and current regulatory institutions (economic autarchies of the 'populist' republic). Normative design is defined as a set of possibilities for an institution's structure and actions which is limited by the legal norms that created it. The model is structured based on two main parameters: independence in relation to the central power and transparency in relation to society. Five hypothesis were tested, and the conclusion was that current regulatory institutions have heterogeneous designs and they differ from the former ones for being both more independent and more transparent, and the largest difference is in the second parameter.
\end{abstract}

\title{
1. Introdução
}

Este artigo apresenta e aplica um modelo matricial para análise dos órgãos estatais de regulação, com base em dois parâmetros centrais dessas instituições públicas: independência em relação ao poder instituidor e transparência da gestão perante a sociedade. Cada um desses parâmetros foi estimado a partir de quatro variáveis analisadas nos textos legais que criaram cada um dos órgãos analisados. Melo (2000) já utilizava um modelo matricial para demonstrar a relação entre delegação e responsabilização em instituições públicas.

Esse modelo de análise compreende a natureza dos órgãos reguladores de acordo com seu desenho normativo, que é entendido como o conjunto de possibilidades de estruturação e de atuação de uma instituição delimitado pelas normas jurídicas que a criaram. Essa classificação é de valia para a diferenciação de órgãos reguladores com base em sua natureza institucional e não em fatores imprecisos como sua denominação.

A análise com base no desenho normativo justifica-se por ser este o fator que mostra o máximo de possibilidades abertas para a entidade sob análise, estabelecendo as "regras do jogo" para uma determinada instituição governamental. Como exemplo podemos citar a previsão legal de fontes próprias de receita para uma determinada agência reguladora. Ainda que na prática de governo tais recursos não sejam disponibilizados com o automatismo previsto no texto legal, este indica o máximo de autonomia financeira atingível por tal organização sem violação da lei. Indica, portanto, o "modelo ideal" pretendido pelo legislador (como representante da sociedade), ao criar tal instituição.

A aplicação do modelo é feita de acordo com uma estratégia de análise bidimensional: o foco transversal analisa entidades contemporâneas entre si e o foco longitudinal analisa instituições reguladoras de dois diferentes perío- 
dos da história nacional: república "populista" (1945-64) e república contemporânea (desde 1985).

A comparação transversal, envolvendo o desenho normativo de diferentes instituições reguladoras da atualidade, permite uma visão mais clara de quão semelhantes (ou distintos) são os desenhos normativos de instituições que atuam nas diversas áreas reguladas. Permite ainda a previsão do impacto das modificações propostas pelo governo para a estrutura das agências reguladoras.

A comparação longitudinal, entre diferentes instituições reguladoras da história brasileira, permite a inserção da discussão atual sobre modelos regulatórios e sobre o papel das agências reguladoras dentro de um contexto nacional, podendo fornecer pistas sobre o "metabolismo" político-institucional de nossa sociedade quando em interação com instituições reguladoras. Pode, por exemplo, evidenciar a distância entre os modelos históricos de regulação no Brasil e os modelos atuais e sugerir caminhos para a pesquisa sobre adequação de modelos ao nosso comportamento político. A rationale é que, se estudos sobre modelos regulatórios estrangeiros podem ser úteis apesar das diferenças sociais existentes, então estudos sobre modelos regulatórios do passado nacional também podem sê-lo, a despeito das peculiaridades sociais de outros períodos de nossa história.

A função regulatória do Estado brasileiro já se fazia sentir na nossa legislação há muito tempo, como atestam os seguintes documentos, disponíveis no site do Senado Federal (www.senado.gov.br):

口 aregimento de 17 de dezembro de 1548 (Governo-Geral de Tomé de Souza): segundo César (1950:18), "traçava normas julgadas necessárias à regulação das relações entre industriais, donos de fábricas e plantadores de cana";

- alvará de 13 de abril de 1809, para se regular o fabrico e o consumo da pólvora;

- decreto de 3 de fevereiro de 1863, que "aprova as tarifas e instruções que devem regular o transporte de passageiros, bagagens, mercadorias etc. na Estrada de Ferro de D. Pedro II";

- decreto de 29 de dezembro de 1880, que "aprova as cláusulas que devem regular as concessões de Estradas de Ferro Gerais no Império";

- Decreto $\mathrm{n}^{\mathrm{O}}$ 5.378, de 14 de dezembro de 1927, que "autoriza a regular o commercio ( $\mathrm{sic}$ ) de café entre os portos do Brasil, e os do exterior e dá outras providencias". 
O estudo da história da regulação estatal no Brasil, portanto, é um campo vasto e potencialmente fértil.

Finalmente, esse modelo de análise permite a realização de estudos futuros comparando o "ideal institucional" previsto na legislação com a realidade institucional do órgão criado.

\section{Referencial teórico}

\section{O conceito de regulação}

Regulação é um conceito que pode ser tomado em diferentes sentidos. As ciências exatas aplicadas fornecem aquele que talvez seja o conceito mais amplo, ao distinguir "servomecanismos" e "mecanismos reguladores" como espécies do gênero "sistemas de controle". Um sistema de controle é um "arranjo de componentes físicos conectados ou relacionados de forma tal a comandar, dirigir ou regular a si mesmo ou a um outro sistema". Um servomecanismo é sistema de controle cuja finalidade é a de amplificar ou transmitir a distância uma variável de comando. O servomecanismo depende de um feedback negativo para interromper sua ação e não está relacionado à manutenção de um determinado efeito específico desejado; seu único objetivo é a transmissão amplificada da variável de controle sem estabelecimento prévio de um nível desejado do efeito dessa variável. Um sistema regulador, por outro lado, preocupa-se em manter o efeito da variável de controle em um nível predeterminado, específico. Um exemplo técnico do primeiro seria a direção hidráulica de automóvel, cuja função é apenas a de transmitir a variável de controle (variação angular da posição do aro de direção) a distância, causando um efeito variável (modificação da posição das rodas). Já um exemplo de mecanismo regulador seria um termostato, utilizado para manter a temperatura de um forno em um nível previamente determinado (Distefano III, Stubberud e Williams, 1990:1-23).

Uma comparação com instituições governamentais é possível. As instituições equivalentes ao grupo dos servomecanismos seriam aqueles órgãos não-autônomos, em cuja função predominaria a execução quase mecânica das ordens dos níveis superiores, como a secretaria executiva de um ministério qualquer. Já a correspondência com os sistemas reguladores poderia ser encontrada nas instituições autônomas da administração indireta, dotadas de alta capacidade de resposta às pressões do meio, com ampla liberdade de ação para implantar as políticas determinadas pelo poder central (as quais seriam equivalentes, nessa comparação, aos níveis predeterminados de efeitos 
que os sistemas reguladores devem manter). Claro que a comparação entre sistemas tecnológicos e sistemas governamentais é imperfeita, mas serve para ilustrar a ampla possibilidade de ruídos de comunicação quando o assunto é regulação.

Já no campo das ciências sociais aplicadas, encontramos divergências entre os autores quanto ao conceito de regulação. Regulação é um "controle mantido durante certo tempo e focalizado, exercido por uma instituição pública sobre atividades que são valorizadas pela comunidade" (Selznick apud Baldwin e Cave, 1999:2). Pode também ser definida como uma das formas de ação do Estado, através do controle do comportamento de firmas e de indivíduos (Viscusi, Vernon e Harrington Jr., 2000:1). Para Abranches (1999:19) "praticamente toda ação do Estado envolve regulação, embora existam campos de intervenção estatal inteiramente dedicados à função regulatória".

Melo (2000:56) identifica quatro tipos modais de ação regulatória do Estado na economia: propriedade pública de firmas ou de setores inteiros da economia; exercício de atividades regulatórias diretamente por departamentos ou órgãos da burocracia executiva; várias formas de auto-regulação por meio de arranjos corporativistas; e regulação pública com regime de propriedade privada.

Como vemos os conceitos de regulação apresentados tangenciam os conceitos de intervenção estatal na economia e até mesmo de atividade estatal lato sensu. Neste artigo definimos regulação como a intervenção do Estado na economia e na atividade social com a finalidade de corrigir falhas de mercado e aumentar o welfare (modificado de Perloff e Carlton, 1994:851-852), sem que tal intervenção implique a produção direta de bens e serviços por instituições estatais. A limitação do conceito de regulação é explicada pela perda de especificidade que sofre o conceito se incluirmos nele qualquer forma de intervenção do Estado na economia. Para justificarmos a utilização dessa definição devemos enfrentar três questões básicas que ela nos propõe sobre a atividade regulatória: o que é um "mercado", quais são as possíveis falhas desse mercado e quais são as possíveis formas de intervenção do Estado na economia.

Mercado é uma estrutura de alocação dos recursos econômicos de uma sociedade através de trocas livres entre compradores e vendedores. É importante notar que a participação do Estado como agente econômico atuando diretamente sobre o mercado não o descaracteriza como tal. Por exemplo, a previsão constitucional da existência de um sistema único de saúde não impede a caracterização da saúde como um mercado.

As falhas do mercado são mais bem definidas a partir de uma discussão sobre o que é um mercado bem-sucedido. Para que isso aconteça é necessário que esse mercado exista e seja suficientemente dimensionado; todos os 
consumidores e produtores ajam de forma competitiva; e exista um ponto de equilíbrio (Ledyard, 1998:326). Um mercado perfeitamente competitivo é um modelo ideal; quando os desvios em relação a esse ideal são muito grandes, torna-se necessária a regulação estatal pelo surgimento de "falhas ou ineficiências" de mercado. Essas falhas podem ser de vários tipos diferentes (Varian, 2003, passim; Baldwin e Cave, 1999:9-33; Laffont, 1998).

Existência de bens públicos - os quais são bens não-rivais e não-excludentes, ou seja: ninguém pode ser excluído de seu consumo, o consumo do bem por um indivíduo não reduz a disponibilidade para outro e não há como evitar que eventuais não-pagantes beneficiem-se dele. Um exemplo é a segurança nacional. A ineficiência gerada pelos bens públicos é a impossibilidade de se cobrar adequadamente por eles, já que não há como evitar os free-riders. O Estado pode intervir diretamente, assumindo a produção de tais bens (intervenção não-regulatória) ou utilizando mecanismos tributários para evitar o problema da não-excludência.

Custos de transação muito elevados - muitas vezes os produtores de uma determinada indústria estão demasiadamente dispersos geograficamente ou são excessivamente pequenos se considerados individualmente. Isso pode gerar ineficiências de mercado por conta de custos de transação proibitivos. A regulação justifica-se aqui por conta da necessidade de coordenação do mercado. Um exemplo é a regulação da produção agrícola. O governo pode assumir o controle dos níveis de produção para evitar excessos, assumindo o papel que seria deixado ao mercado se os custos de transação relacionados a tal atividade não fossem tão elevados.

Comportamento não-competitivo - os mercados perfeitamente competitivos são, como afirmamos acima, mais um modelo que uma realidade. As formas de mercado não-competitivo que podem surgir (monopólio, oligopólio, monopsônio, oligopsônio) devem ser corrigidas em benefício da sociedade. Temos aqui o campo tanto da atividade antitruste quanto da regulação dos monopólios naturais (setores da atividade econômica nos quais, por exemplo, há grandes custos fixos e pequenos custos marginais). Exemplos de monopólios naturais são as public utilities: gás, água encanada, energia elétrica, petróleo, telecomunicações. Nessas atividades, a introdução de novos atores é ineficiente: os custos de entrada são tão elevados que muitas vezes uma única empresa irá produzir de forma mais racional, desde que o regulador reproduza as pressões de mercado sobre preço e qualidade.

Assimetria de informação - um dos elementos essenciais para o funcionamento perfeito de um mercado é a possibilidade de que seus agentes ajam de forma perfeitamente competitiva. Um dos pressupostos para que isso ocorra é a perfeita transmissão de informação sobre preço e qualidade dos produtos e ser- 
viços oferecidos. Quando um dos dois agentes (comprador ou vendedor) detém mais informações que o outro, ineficiências de mercado surgirão. Um exemplo vem do mercado de seguros: uma seguradora deve considerar que seus segurados provirão, em geral, das camadas da população mais expostas ao sinistro segurado. Em conseqüência, seus cálculos atuariais devem levar em consideração a incidência desses eventos entre as populações mais atingidas para que o prêmio do seguro seja adequado. Se a seguradora calcular o prêmio de seu seguro pela média de sinistralidade na população como um todo, o prêmio atrairá justamente aqueles que sabem ser sua possibilidade de exposição ao sinistro maior que a da média da população e a empresa enfrentará muitas dificuldades. A esse fenômeno chamamos de seleção adversa, pois o comprador do seguro possui informações mais completas sobre a sua exposição a sinistros e, portanto, sobre a precificação do seguro. O papel do governo consiste em procurar garantir as informações sobre qualidade e preço de produtos e serviços de maneira a aumentar a competitividade do mercado. Um exemplo recente em nosso meio é a criação do "selo" de medicamento genérico pelo governo brasileiro (ver <www.anvisa.gov.br>, diversas páginas e informações a respeito). Ao afirmar que determinado medicamento é "genérico" o governo está oferecendo ao mercado garantias quanto à sua qualidade, permitindo sua adequada precificação.

Externalidades são efeitos indiretos (positivos ou negativos) de uma atividade de consumo ou de produção sobre a atividade de outros produtores ou consumidores e que não podem ser adequadamente negociados em um mercado. Um exemplo é a poluição de rios por fábricas. O produtor utiliza um recurso da coletividade (a limpeza das águas do rio) para seu benefício, pois poluir o rio é mais eficiente financeiramente (ao menos no curto prazo) que instalar equipamentos antipoluentes. Caso não haja uma fiscalização por parte do Estado, essa atividade permanecerá. O problema por trás desse fenômeno é a falta de mercados para essas externalidades. Ao multar a atividade poluente, o Estado "precifica" a limpeza do rio, inibindo a atividade poluente da empresa. Vale lembrar que externalidades também podem ser positivas, caso em que o Estado deve agir incentivando-as, ou seja, fornecendo algum tipo de benefício equivalente ao "pagamento de um preço" pela atividade a ser estimulada.

As possíveis formas de intervenção regulatória do Estado na economia são variações sobre duas possibilidades básicas: estímulos em relação a preços ou controle do comportamento dos agentes de forma direta (Viscusi, Vernon e Harrington Jr., 2000:3).

Em síntese, segundo a definição empregada neste artigo para o termo regulação, a produção direta de bens e serviços não pode ser considerada ati- 
vidade regulatória. Em outras palavras, nesta definição a regulação é espécie do gênero intervenção estatal na economia e na atividade social. Portanto, podemos definir instituições públicas reguladoras como aquelas instituições da administração pública direta ou indireta responsáveis pela intervenção na atividade econômica ou social visando a correção das falhas do mercado, sem que tal intervenção represente a produção direta pelo Estado dos bens envolvidos. Isso nos leva à próxima questão relacionada às instituições públicas reguladoras: qual é o grau de autonomia que estas devem possuir em relação ao poder central? Para que essa questão possa ser atacada, é preciso discutir alguns conceitos relacionados à administração pública.

\section{Administração pública direta e indireta: autonomia das instituições reguladoras públicas}

Quando pensamos na administração pública, a primeira imagem que talvez venha à nossa mente é a dos órgãos do poder central: presidência e ministérios (esfera federal), governos estaduais e secretarias (esfera estadual), prefeituras e secretarias municipais (esfera municipal). Esses órgãos, entretanto, não podem concentrar todas as decisões e ações necessárias para a administração do país. Em virtude da dimensão e do escopo de sua atuação e da diversidade dos assuntos e interesses com os quais está envolvida a administração pública, é impossível para seus órgãos principais controlar de forma centralizada toda a atividade necessária. Em virtude disso, existe um processo de distribuição de competências a outras instituições do poder público, que podem tomar determinadas decisões necessárias para a execução de suas atividades sem consultar os órgãos da administração central. Essa transferência de graus variados de autonomia pode se dar de duas formas distintas: desconcentração e descentralização (Di Pietro, 2002:349).

Na desconcentração, existe a distribuição interna de competências: uma pessoa jurídica de direito público cria, em sua estrutura administrativa, órgãos responsáveis por determinadas atividades, com certas competências determinadas. Por exemplo: o Ministério da Saúde cria uma Secretaria de Ciência e Tecnologia. Trata-se de um órgão que não possui autonomia jurídica em relação ao ministério; é parte deste. Não pode ser parte em uma ação judicial, por exemplo (a parte seria o "Ministério da Saúde"). Sua relação com o ministério é de subordinação hierárquica.

Na descentralização, existe a criação, por lei, de uma nova pessoa jurídica, vinculada a um órgão do poder central porém autônoma em relação a ele. É o caso das autarquias, das fundações instituídas pelo poder público, das 
sociedades de economia mista e empresas estatais. Vale lembrar que as atuais "agências reguladoras" são juridicamente autarquias, qualificadas como especiais em virtude de maior autonomia em relação ao poder central. Nenhuma delas, entretanto, é "independente", já que uma autarquia, em nosso direito, é sempre vinculada a algum órgão da administração central (no caso, ministérios).

Esses conceitos permitem que definamos administração pública direta e indireta: administração direta compreende os serviços integrados na estrutura administrativa da presidência da República (ministérios), dos governos estaduais (secretarias estaduais) e do Distrito Federal e das prefeituras (secretarias municipais). Administração indireta é o conjunto de pessoas jurídicas, de direito público (autarquias e fundações) e de direito privado (sociedades de economia mista e empresas estatais), criadas por lei, para desempenhar atividades assumidas pelo Estado, seja como serviço público, seja a título de intervenção no domínio econômico (Di Pietro, 2002:360-361). É importante notar que as entidades da administração pública direta são subordinadas hierarquicamente à direção do órgão a que pertencem enquanto as entidades da administração pública indireta são apenas tuteladas pelo órgão a qual estão vinculadas, mas mantêm em relação a este um grau de autonomia conforme a previsão da lei que as tenha criado.

Podemos agora nos questionar quanto aos motivos que levam o poder público a decidir por uma ou por outra forma de gestão da administração pública: desconcentração ou descentralização. A resposta não é simples. Especificamente em relação à atividade de regulação, há muitas divergências quanto à necessidade de descentralização da atividade regulatória e também quanto ao grau de autonomia ("independência") a ser concedido às entidades recémcriadas.

Segundo Baldwin e Cave (1999:63), "a regulação pode ser empreendida por uma variedade de órgãos e a natureza das instituições pode afetar não somente o estilo da regulação e as estratégias empregadas mas também o sucesso das intenções regulatórias". Esse fato sugere a necessidade de se possuir uma forma de classificação das entidades regulatórias de acordo com sua natureza institucional, como por exemplo o desenho normativo delas. E dentro desse objetivo, os dois critérios que se destacam são a independência em relação ao poder central e transparência de sua gestão. A primeira característica é relevante em virtude da possibilidade de que órgãos independentes ajam de forma a priorizar a excelência técnica das decisões em vez da conveniência política. Por outro lado, a transparência de uma entidade pública dotada de certo grau de autonomia é essencial para que se possa aferir a lisura 
de seu processo decisório, assegurando à sociedade que os interesses defendidos sejam os seus, e não os de algum grupo específico apenas.

Portanto, se pudermos classificar as entidades reguladoras a partir de seu desenho normativo, teremos uma base cognitiva objetiva sobre a qual é possível erigir uma teoria da ação dessas entidades, da mesma forma que a objetividade da anatomia permite o desenvolvimento de estudos sobre a fisiologia, para utilizarmos uma comparação das ciências biológicas.

\section{Metodologia}

Para a realização da análise comparativa foi desenvolvido um modelo matricial tendo por base dois parâmetros de avaliação: independência do órgão regulador em relação ao poder central e a transparência do órgão em relação à sociedade. Melo (2000:59-63) já utiliza o modelo matricial para uma classificação genérica dos órgãos da administração, utilizando os critérios de responsabilização e de delegação. No modelo em discussão, cada um dos parâmetros por sua vez é o resultado da soma de quatro variáveis. O valor máximo de independência e de transparência nesse modelo é quatro e o mínimo é zero. Como detalhado previamente neste artigo, o valor dessas variáveis é extraído da análise dos textos das leis ou normas equivalentes que instituíram os órgãos. Os textos legais foram obtidos nos sites da presidência da República (www.planalto.gov.br) ou no do Senado (www.senado.gov.br). As variáveis utilizadas na estimação de cada parâmetro são apresentadas a seguir.

\section{口 Independência (IND)}

- Pessoa jurídica distinta (PJD): no caso do órgão regulador constituir pessoa jurídica distinta da pessoa jurídica que o instituiu (União, estado, Distrito Federal ou município), o valor da variável é 1 , de outra forma é 0 . A justificativa é a autonomia inerente aos órgãos da administração pública indireta em relação ao poder central.

- Contrato de gestão (CG): o contrato de gestão é um fator de redução da independência das agências reguladoras. O controle por parte do Executivo, pela instituição desse instrumento, vincula, em maior ou menor grau, a autonomia gerencial dos dirigentes dos órgãos reguladores, seja pela imposição de metas cuja adequação é muitas vezes questionada, seja pela própria necessidade de negociação mais intensa com o poder instituidor. Como é um fator de redução da independência, a existência do contrato soma 0 e sua inexistência soma 1 . 
- Fonte própria de recursos (FPR): a existência da previsão de recursos próprios para os órgãos reguladores aumenta sua independência em relação ao poder central. Havendo previsão de tais recursos, soma-se 1 , de outra forma soma-se 0 .

- Mandato fixo dos dirigentes (MF): a fixação do mandato dos membros da direção dos órgãos reguladores é um fator de independência em virtude da garantia de manutenção do cargo diante de eventuais pressões do poder central. Soma 1 ponto.

\section{口 Transparência (TR)}

- Contrato de gestão (CG): Se a existência de um contrato de gestão por um lado reduz a independência de uma instituição reguladora, por outro, aumenta a transparência de sua gestão perante seus stakeholders, pois permite uma compreensão melhor da relação entre meios utilizados e fins pretendidos. Soma 1 ponto.

- Decisão colegiada (DC): é importante por reduzir, ou ao menos dificultar, a "captura" do poder decisório da instituição por grupos de interesse. Havendo decisão colegiada computa-se 1; de outra forma, 0.

- Consulta pública (CP): a obrigatoriedade da consulta pública em relação aos atos normativos mais importantes para o setor regulado também serve como fator de aumento da transparência dos processos decisórios, pois mesmo que as sugestões não sejam incorporadas ao texto final, os stakeholders passam a ter uma compreensão mais clara dos fatores envolvidos nas tomadas de decisão dentro da instituição. Importante notar que a pontuação (1 ponto) para existência de consulta pública ocorre apenas na previsão da obrigatoriedade da mesma, e não da consulta pública realizada por decisão discricionária da diretoria (que, portanto, também poderia optar por não realizá-la).

- Existência de ouvidoria (OUV): outra ferramenta de controle social e de transparência. Caso haja ouvidoria, conta-se 1 ponto; de outra forma, 0.

\section{Instituições reguladoras analisadas}

Contemporâneas. O quadro adiante apresenta as entidades regulatórias contemporâneas analisadas neste artigo, relacionando nome, ato de criação e mercado ou atividade regulada. 
As agências incluídas têm sua presença justificada pela sua definição como tal (direta ou indiretamente) nos atos que as instituíram e também por estarem relacionadas como tal no projeto de lei enviado ao Congresso em abril de 2004 pela presidência da República, que visa alterar as leis de instituição das agências reguladoras. Já a inclusão da Câmara Reguladora do Mercado de Medicamentos é resultado de sua definição como órgão regulador no ato que a criou.

\begin{tabular}{|c|c|c|}
\hline \multicolumn{3}{|c|}{ Instituições da atualidade analisadas neste artigo } \\
\hline Instituição & Criação & $\begin{array}{l}\text { Mercado/atividades } \\
\text { reguladas }\end{array}$ \\
\hline $\begin{array}{l}\text { Anatel — Agência Nacional de } \\
\text { Telecomunicações }\end{array}$ & $\begin{array}{l}\text { Lei } n^{0} 9.472 \text {, de } 16 \text { de } \\
\text { julho de } 1997\end{array}$ & Telecomunicações \\
\hline $\begin{array}{l}\text { Aneel — Agência Nacional de Energia } \\
\text { Elétrica }\end{array}$ & $\begin{array}{l}\text { Lei } \mathrm{n}^{0} 9.427 \text {, de } 26 \text { de } \\
\text { dezembro de } 1996\end{array}$ & $\begin{array}{l}\text { Produção, transmissão, distribuição } \\
\text { e comercialização de energia elétrica }\end{array}$ \\
\hline $\begin{array}{l}\text { ANP — Agência Nacional do } \\
\text { Petróleo }\end{array}$ & $\begin{array}{l}\text { Lei } n^{0} 9.478 \text {, de } 6 \text { de } \\
\text { agosto de } 1997\end{array}$ & Indústria do petróleo \\
\hline $\begin{array}{l}\text { ANA — Agência Nacional de } \\
\text { Águas }\end{array}$ & $\begin{array}{l}\text { Lei } n^{0} 9.984 \text {, de } 17 \text { de } \\
\text { julho de } 2000\end{array}$ & Recursos hídricos \\
\hline $\begin{array}{l}\text { ANTT — Agência Nacional de } \\
\text { Transportes Terrestres }\end{array}$ & $\begin{array}{l}\text { Lei n- } 10.233 \text {, de } 5 \text { de } \\
\text { junho de } 2001\end{array}$ & $\begin{array}{l}\text { Infra-estrutura de transportes } \\
\text { terrestres }\end{array}$ \\
\hline $\begin{array}{l}\text { Antaq - Agência Nacional de } \\
\text { Transportes Aquaviários }\end{array}$ & $\begin{array}{l}\text { Lei } n^{0}-10.233 \text {, de } 5 \text { de } \\
\text { junho de } 2001\end{array}$ & $\begin{array}{l}\text { Infra-estrutura de transportes } \\
\text { aquaviários }\end{array}$ \\
\hline $\begin{array}{l}\text { Anvisa - Agência Nacional de } \\
\text { Vigilância Sanitária }\end{array}$ & $\begin{array}{l}\text { Lei } n^{0} 9.782 \text {, de } \\
26 \text { de janeiro de } \\
1999\end{array}$ & $\begin{array}{l}\text { Produção e comercialização de } \\
\text { produtos e serviços submetidos à } \\
\text { vigilância sanitária }\end{array}$ \\
\hline $\begin{array}{l}\text { ANS — Agência Nacional } \\
\text { de Saúde }\end{array}$ & $\begin{array}{l}\text { Lei n- } 9.961 \text {, de } 28 \text { de } \\
\text { janeiro de } 2000\end{array}$ & $\begin{array}{l}\text { Assistência suplementar } \\
\text { à saúde }\end{array}$ \\
\hline $\begin{array}{l}\text { Ancine - Agência Nacional } \\
\text { do Cinema }\end{array}$ & $\begin{array}{l}\text { Medida Provisória } \\
\mathrm{n}^{0}-2.228-1 \text {, de } 6 \\
\text { de setembro de } 2001\end{array}$ & $\begin{array}{l}\text { Indústria cinematográfica e } \\
\text { videofonográfica }\end{array}$ \\
\hline $\begin{array}{l}\text { CMED — Câmara de Regulação } \\
\text { do Mercado de Medicamentos }\end{array}$ & $\begin{array}{l}\text { Lei } \mathrm{n}^{0}-10.742 \text {, de } 6 \text { de } \\
\text { outubro de } 2003\end{array}$ & Mercado de medicamentos \\
\hline
\end{tabular}

República "populista”. Seguindo o projeto inicial de comparar as entidades reguladoras contemporâneas também com entidades reguladoras de 
nosso passado, incluímos cinco autarquias já extintas que, a nosso ver, desempenhavam uma função reguladora. Já em 1950 César (p. 14) escrevia: "Conquanto os órgãos autárquicos - genericamente falando - integrem importante setor da administração indireta, o nosso objetivo neste estudo envolve, apenas, os institutos reguladores da economia, por intermédio dos quais o Estado interveio no campo da produção". A classificação dessas autarquias como entidades reguladoras é justificada pelo fato de preencherem todos os requisitos de nossa definição: são entidades públicas, não têm função precípua de produção e intervêm no mercado corrigindo falhas, em geral aquelas associadas a elevados custos de transação que impedem uma adequada articulação entre produtores, e corrigindo assimetrias de informação ao tentar padronizar os produtos. A seguir uma descrição das instituições estudadas.

- Instituto do Açúcar e do Álcool (IAA). Criado em 1933 em virtude, entre outros fatores, da "necessidade de assegurar o equilíbrio do mercado de açúcar conciliando, do melhor modo, os interesses de produtores e consumidores". Seria extinto apenas em 1990 pela Lei $n^{0} 8.029$. O texto analisado aqui é o Decreto $\mathrm{n}^{\mathrm{O}}$ 29.118, de 10 de janeiro de 1951, que reorganizou o instituto.

- Instituto Nacional do Mate (INM). Criado pelo Decreto-Lei no 375 , de 13 de abril de 1938, o órgão tinha por função "coordenar e superintender os trabalhos relativos à defesa de sua produção [do mate], comércio e propaganda". $\mathrm{O}$ art. $1^{\underline{\mathrm{o}}}$ de seu ato de criação previa que o órgão seria "administrativa e financeiramente autônomo". Foi extinto pelo Decreto-Lei no 281 , de 28 de fevereiro de 1967. O ato analisado aqui é o Decreto-Lei no 8.709 , de 17 de janeiro de 1946, que reorganizou o instituto.

- Instituto Nacional do Sal (INS). Criado em 10 de junho de 1940 (DecretoLei $\mathrm{n}^{\mathrm{o}}$ 2.300), o instituto tinha como função, entre outras, "assegurar o equilíbrio da produção de sal com o seu consumo" e "fixar os tipos do produto". O ato analisado aqui é a Lei no 3.137 , de 13 de maio de 1957, que reestruturou o instituto. Foi extinto pelo Decreto-Lei $n^{\circ}$ 257, de 28 de fevereiro de 1967, sendo substituído por uma instituição da administração direta, a "Comissão Executiva do Sal, [...] órgão integrante do Ministério da Indústria e do Comércio".

- Instituto Nacional do Pinho (INP). Criado em 19 de março de 1941, pelo Decreto-Lei $n^{0}$ 3.124, o instituto tinha, entre suas competências, "regular a instalação de novas serrarias, fábricas de caixas e de beneficiamento de madeira", "fixar preços mínimos; estabelecer quotas de produção e de exportação"; e "manter, em colaboração com o Ministério da Agricultura, a padro- 
nização e a classificação oficial do pinho". O ato aqui analisado é o Decreto n- 20.471, de 28 de fevereiro de 1946, que publicou um novo regulamento, reestruturando o órgão. O INP foi extinto em 28 de fevereiro de 1967 (Decreto-Lei $n^{0}$ 289).

- Instituto Brasileiro do Café (IBC). Criado pela Lei $\mathrm{n}^{0}$ 1.779, de 22 de dezembro de 1952, o IBC destinava-se a "realizar política econômica do café brasileiro no país e no estrangeiro", e entre suas diretrizes incluía-se a "defesa de um preço justo para o produtor, condicionado à concorrência da produção alienígena e dos artigos congêneres, bem assim à indispensável expansão do consumo". Entre outras, tinha as atribuições de "regular a entrada nos portos, definindo o limite máximo dos estoques liberados em cada um deles" e de "definir a qualidade dos cafés de mercado para o consumo do interior e do exterior, regulamentando e fiscalizando os tipos e qualidades no comércio interno e na exportação, podendo adotar medidas que assegurem o normal abastecimento do mercado interno". Foi extinto em 1990, pela Lei no 8.029 .

A figura 1 mostra uma aplicação hipotética do modelo para duas instituições reguladoras distintas: a instituição B soma 4 pontos em "independência" (é uma pessoa jurídica distinta, não está submetida a contrato de gestão, seus dirigentes possuem mandatos fixos e há fonte própria de recursos) e 3 pontos em transparência (não há contrato de gestão, há ouvidor, há obrigatoriedade de consulta pública e as decisões são colegiadas). A instituição A, por outro lado, soma 1 ponto em independência e 1 ponto em transparência.

Figura 1

Modelo matricial

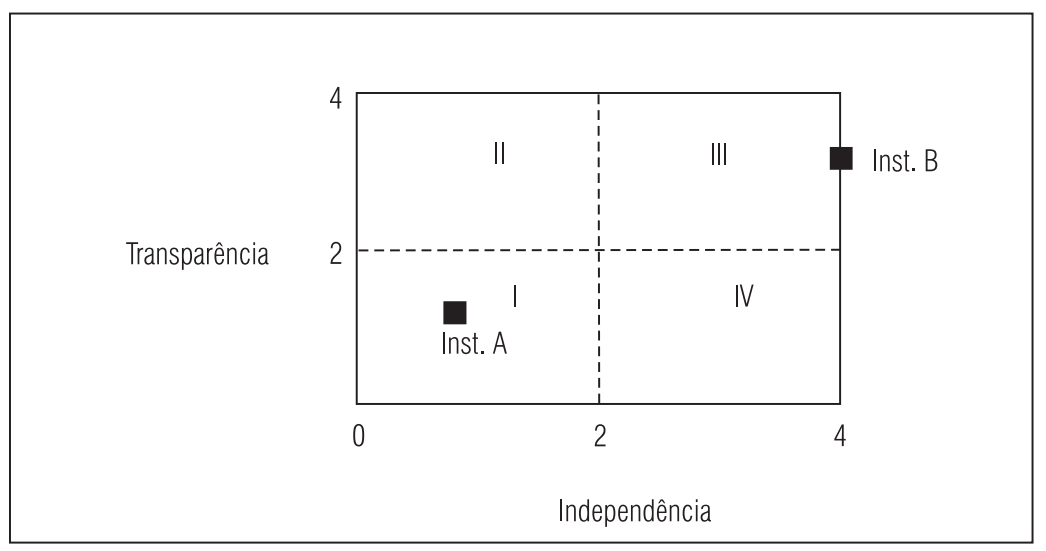


No eixo $x$, estão os pontos relativos à independência e no eixo $y$ os pontos relativos à transparência. Com um ponto em cada parâmetro, a instituição A está localizada no quadrante I, enquanto a instituição B, com 4 pontos (independência) e 3 pontos (transparência), está situada no quadrante III (maior independência e transparência).

\section{Hipóteses}

- Ha. As diversas entidades reguladoras contemporâneas apresentam diferentes classificações neste modelo em função de sua transparência e independência. Essa hipótese verifica se há ou não um padrão homogêneo de "entidade reguladora" e nos dá uma indicação das diferenças de desenho normativo entre elas.

- Ha'. As instituições reguladoras do setor de infra-estrutura diferem entre si, e da mesma forma diferem entre si as instituições reguladoras dos setores "sociais".

- Hb. A pontuação média entre agências reguladoras dos setores de infra-estrutura (Anatel, Aneel, ANTT, Antaq, ANP e ANA) é maior que a pontuação média das agências reguladoras de setores "sociais" (Anvisa, ANS, Ancine). Essa hipótese avalia se é possível traçarmos um paralelo, em termos de desenho institucional, entre as agências do setor de infra-estrutura (que procuram corrigir também as imperfeições de mercado decorrentes da existência de monopólios naturais) e as agências reguladoras dos setores "sociais" da cultura e da saúde, as quais a princípio enfrentam com mais intensidade imperfeições de mercado decorrentes de assimetrias de informação e elevados custos de transação.

- $\quad$ Hb'. A diferença entre as agências reguladoras do setor de infra-estrutura e do setor "social" dá-se em função do fator transparência e não em função do fator independência.

- Hc. As diferenças em termos de independência e de transparência entre as agências reguladoras atuais e as autarquias econômicas da república "populista" permite superposição, ou seja, pelo menos uma das autarquias econômicas possui uma pontuação total igual ou maior à pontuação de pelo menos uma das agências reguladoras da atualidade.

- Hd. A diferença da média das pontuações entre instituições reguladoras da atualidade e do passado é maior tanto no parâmetro "independência" quanto no parâmetro "transparência", mas é maior no segundo do que no primeiro. 


\section{Resultados e discussão}

A tabela 1 apresenta os valores encontrados para os dois parâmetros, independência (IND) e transparência (TR), e para as diversas variáveis.

\begin{tabular}{|c|c|c|c|c|c|c|c|c|c|c|c|}
\hline & Valores & $\begin{array}{r}\text { ada } v \\
\text { nas }\end{array}$ & $\begin{array}{l}\text { ariá } \\
\text { enti }\end{array}$ & $\begin{array}{l}\text { Tabel } \\
\text { el e } \\
\text { lade }\end{array}$ & $\begin{array}{c}1 \\
\text { otal } \\
\text { est }\end{array}$ & $\begin{array}{l}\text { oara } \\
\text { Idac }\end{array}$ & $\begin{array}{l}\text { cad } \\
\text { as }\end{array}$ & pal & àmet & & \\
\hline № & Instituição & PJD & CGI & FPR & MF & $\mathrm{DC}$ & OUV & $\mathrm{CP}$ & CGT & IND & $\mathrm{TR}$ \\
\hline 1 & Anatel & 1 & 1 & 1 & 1 & 1 & 1 & 1 & 0 & 4 & 3 \\
\hline 2 & Aneel & 1 & 0 & 1 & 1 & 1 & 1 & 1 & 1 & 3 & 4 \\
\hline 3 & ANP & 1 & 1 & 1 & 1 & 1 & 0 & 1 & 0 & 4 & 2 \\
\hline 4 & Anvisa & 1 & 0 & 1 & 1 & 1 & 1 & 0 & 1 & 3 & 3 \\
\hline 5 & ANS & 1 & 0 & 1 & 1 & 1 & 1 & 0 & 1 & 3 & 3 \\
\hline 6 & Antaq & 1 & 1 & 1 & 1 & 1 & 1 & 1 & 0 & 4 & 3 \\
\hline 7 & ANTT & 1 & 1 & 1 & 1 & 1 & 1 & 1 & 0 & 4 & 3 \\
\hline 8 & ANA & 1 & 1 & 1 & 1 & 1 & 0 & 0 & 0 & 4 & 1 \\
\hline 9 & Ancine & 1 & 1 & 1 & 1 & 1 & 1 & 0 & 0 & 4 & 2 \\
\hline 10 & CMED & 0 & 0 & 0 & 0 & 1 & 0 & 0 & 0 & 0 & 1 \\
\hline 11 & INM & 1 & 1 & 1 & 0 & 1 & 0 & 0 & 0 & 3 & 1 \\
\hline 12 & $\mathrm{IAA}$ & 1 & 1 & 1 & 0 & 1 & 0 & 0 & 0 & 3 & 1 \\
\hline 13 & INP & 1 & 1 & 1 & 0 & 1 & 0 & 0 & 0 & 3 & 1 \\
\hline 14 & $\mathrm{IBC}$ & 1 & 1 & 1 & 0 & 1 & 0 & 0 & 0 & 3 & 1 \\
\hline 15 & INS & 1 & 1 & 1 & 0 & 1 & 0 & 0 & 0 & 3 & 1 \\
\hline
\end{tabular}

Hipótese a: confirmada - hipótese a': confirmada

Para testá-las, utilizamos o modelo da figura 1, resultante da plotagem no eixo $x$ da soma total das variáveis do parâmetro independência e no eixo $y$ da soma total das variáveis do parâmetro transparência, incluídas aqui as 10 instituições atuais de regulação e também as instituições da república "populista" (Rep. Pop.). O resultado está na figura 2. 
Figura 2

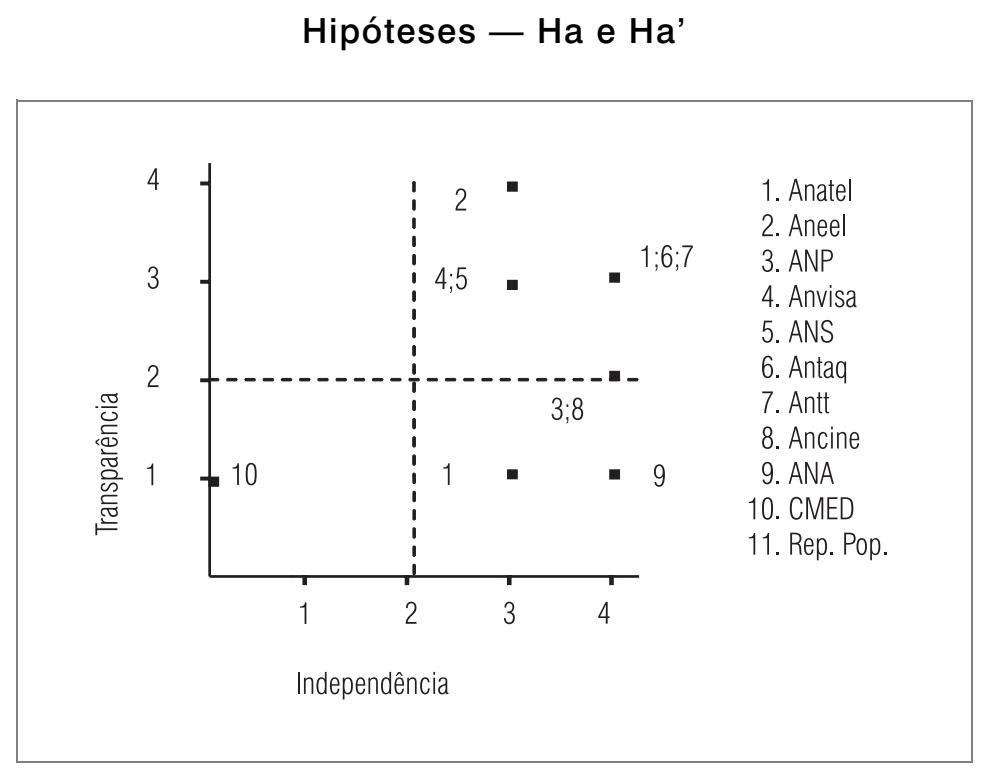

A análise do gráfico confirma a hipótese a (Ha): as entidades reguladoras atuais diferem quanto a seu desenho institucional. Seis situam-se no quadrante III (alta independência, alta transparência). A Agência Nacional do Cinema e a Agência Nacional do Petróleo situam-se no limite dos dois quadrantes de maior independência e a Agência Nacional das Águas (ANA) situase no quadrante IV, com alta independência, porém baixa transparência. $\mathrm{O}$ caso mais interessante talvez seja o da Câmara de Regulação do Mercado de Medicamentos (CMED). Com 0 de independência (é um órgão dentro da estrutura da Casa Civil) e pouca transparência, mostra como o desenho normativo por si só não protege o modelo regulatório independente. Criada após a Anvisa, "capturou" competências dessa agência, que se limita a compor a Secretaria Executiva da Câmara. Também vale ressaltar a posição inferior da ANP em relação a Anatel, ANTT, Antaq e Aneel (infra-estrutura). A agência do petróleo apresenta um desenho normativo de classificação inferior ao das agências de saúde.

Confirma-se ainda a hipótese a' (Ha'), pois as instituições de infra-estrutura diferem entre si, da mesma forma que as instituições dos setores "sociais" (Anvisa, ANS, Ancine). 
Hb: confirmada - Hb': rejeitada

A tabela 2 mostra o resultado da média de pontos para cada parâmetro nas agências reguladoras de infra-estrutura (Anatel, Aneel, ANP, Antaq, ANTT e ANA) e nas agências reguladoras de setores "sociais" (ANS, Anvisa, Ancine).

\begin{tabular}{|lcc|}
\hline \multicolumn{3}{|c|}{$\begin{array}{c}\text { Tabela } 2 \\
\text { Hipóteses Hb e Hb': agências de infra-estrutura } \\
\text { e de regulação “social” }\end{array}$} \\
\hline Parâmetro & Agência social & Agência de infra-estrutura \\
\hline IND & 3,33 & 3,83 \\
TR & 2,67 & 2,67 \\
Total & 3 & 3,25 \\
\hline
\end{tabular}

Os achados confirmam a hipótese $\mathrm{b}(\mathrm{Hb})$ de que a pontuação das agências de infra-estrutura (IE) é mais alta do que a pontuação das agências reguladoras de setores sociais (SOC). Entretanto, a hipótese b' (Hb') não se confirma, pois é justamente o fator independência que eleva a pontuação das agências de infra-estrutura. A figura 3 permite a análise visual.

Figura 3

Agências de infra-estrutura $x$ agências de setores sociais

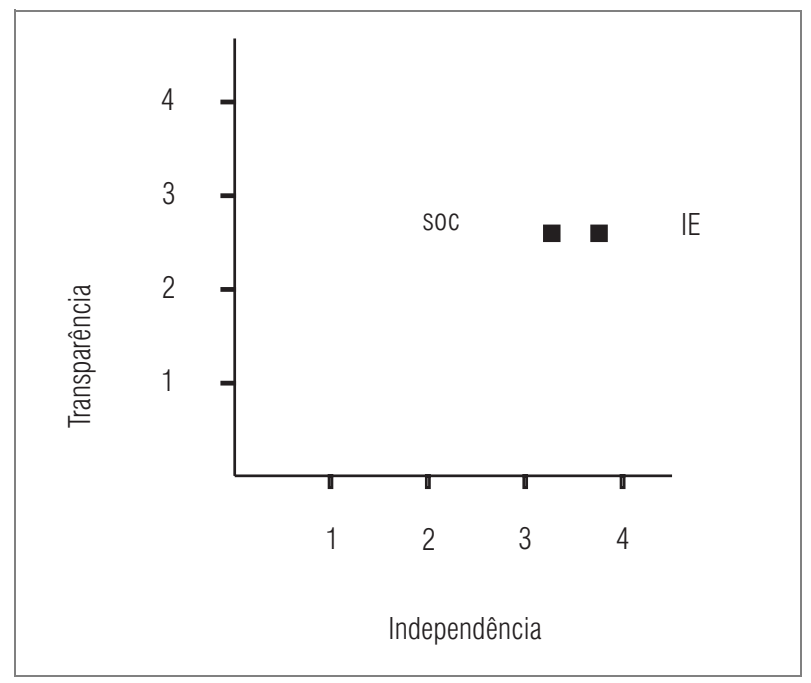

RAP Rio de Janeiro 40(4):589-613, Jul./Ago. 2006 
A questão que se coloca é qual pode ser a lógica por trás desse fato. A princípio, por lidarem com monopólios naturais, as agências de infra-estrutura deveriam apresentar uma alta transparência, para inspirar a confiança dos investidores. Os resultados são "puxados" para baixo pela baixa pontuação em transparência no desenho normativo de ANA e de ANP.

\section{Hipótese c: confirmada}

Para testar a hipótese c (Hc), analisamos a tabela 3 e observamos que uma das instituições reguladoras da atualidade, a CMED, apresenta uma pontuação total (1) inferior à das quatro autarquias econômicas da república "populista", ou seja: não se pode dizer que a "regulação" estatal seja hoje uniformemente realizada por instituições mais independentes e transparentes que no passado. Por outro lado, notamos que as agências reguladoras apresentam pontuações superiores às de quaisquer agências reguladoras da república "populista", apesar da pontuação da ANA ser apenas 1 ponto superior à pontuação das instituições do passado.

\begin{tabular}{|ccccc|}
\hline \multicolumn{5}{c|}{ Tabela 3} \\
\multicolumn{5}{|c|}{$\begin{array}{c}\text { Pontuação total das instituições reguladoras da atualidade } \\
\text { e das autarquias econômicas da república “populista” }\end{array}$} \\
\hline № & Instituição & IND & TR & Total \\
\hline 1 & Anatel & 4 & 3 & 7 \\
2 & Aneel & 3 & 4 & 7 \\
3 & ANP & 4 & 2 & 6 \\
4 & Anvisa & 3 & 3 & 6 \\
5 & ANS & 3 & 3 & 6 \\
6 & Antaq & 4 & 3 & 7 \\
7 & ANTT & 4 & 3 & 7 \\
8 & ANA & 4 & 1 & 5 \\
9 & Ancine & 4 & 2 & 6 \\
10 & CMED & 0 & 1 & 1 \\
11 & INM & 3 & 1 & 4 \\
12 & IAA & 3 & 1 & 4 \\
13 & INP & 3 & 1 & 4 \\
14 & IBC & 3 & 1 & 4 \\
15 & INS & 3 & 1 & 4 \\
\hline
\end{tabular}




\section{Hd: confirmada}

Finalmente, para testar a hipótese d (Hd), apresentamos a tabela 4, comparando as médias de pontuação das instituições do presente (Atual) e autarquias da república "populista" (Aut. RP), nos dois parâmetros, independência (IND) e transparência (TR).

\begin{tabular}{|lcc|}
\hline \multicolumn{3}{|c|}{ Tabela 4} \\
\begin{tabular}{|l} 
Pontuação média das instituições reguladoras \\
do presente e da república "populista"
\end{tabular} \\
\hline & IND & TR \\
\hline Atual & 3,3 & 2,85 \\
Aut. RP & 3 & 1 \\
\hline
\end{tabular}

Confirmando a hipótese d, a pontuação média dos dois grupos é maior para as instituições do presente, tanto no parâmetro independência quanto no parâmetro transparência, e é maior para transparência do que para independência, tanto em valores absolutos (1,5 e 0,3, respectivamente) quanto em valores percentuais ( $150 \%$ e $10 \%$, respectivamente).

O modelo revela alguns dados interessantes. Em primeiro lugar, destacase a heterogeneidade do desenho institucional das agências reguladoras da atualidade. Longe de seguir um padrão relacionado ao tipo de falha de mercado regulada ou setor regulado, seu desenho parece ser o resultado da complexa interação entre necessidade de eficiência técnica e possibilidades políticas. O impacto do projeto de lei apresentado pela presidência da República em abril, modificando o desenho institucional das agências poderá ser objeto de estudos futuros nesse sentido.

Outro ponto interessante é a constatação da evolução temporal do conceito de necessidade de transparência da administração pública nas últimas décadas. As autarquias econômicas das décadas de 1940 e 1950 são pouco menos independentes (em seu desenho normativo) do que as agências reguladoras da atualidade, mas seu desenho institucional contempla muito menos a transparência do que suas congêneres contemporâneas. Futuros estudos podem acompanhar de forma mais aprofundada a evolução histórica da regulação em nosso país, os pontos de vulnerabilidade e sua relação com as práticas políticas e sociais do nosso meio.

RAP Rio de Janeiro 40(4):589-613, Jul./Ago. 2006 
Também, a presença de uma instituição como a Câmara de Regulação do Mercado de Medicamentos (CMED) merece estudos mais aprofundados. Em completa "contramão" histórica, a instituição, reguladora de um mercado extremamente importante, parece tratar a regulação dessa atividade como "política de Estado" no sentido mais estrito da expressão. O efeito em longo prazo desse desenho normativo merece ser acompanhado, quando não comparado com outras instituições. Também a relação da CMED com a Anvisa poderá ser objeto de estudos futuros.

Finalmente, uma implicação desse estudo para a gestão pública é a possibilidade de se comparar eficiência técnica e desenho normativo, por um lado, e desenho normativo com realidade gerencial e política, por outro. Em outras palavras, quanto um desenho normativo que favorece a transparência efetivamente irá garanti-la? E se o desenho normativo não garante independência e transparência, quais são os fatores limitantes? Da mesma forma, a classificação das instituições reguladoras a partir de seu desenho normativo permite sua correlação com eficiência e com as necessidades gerenciais da regulação de cada mercado.

\section{Limitações do estudo}

Já se disse certa feita que todos os modelos são errados, mas alguns deles são úteis. Algumas limitações desse modelo são comuns a qualquer outro modelo: seleção de parâmetros e de variáveis, peso de cada uma delas, seleção da amostra analisada. A possibilidade de se classificar as instituições reguladoras a partir de seu desenho normativo, entretanto, justifica a tentativa de se desenvolver o modelo. Novos estudos poderão sofisticá-lo e mesmo adequá-lo a diferentes usos. Por outro lado, a seleção da amostra merece algumas ressalvas. A limitação de tempo e de espaço deste artigo não permite uma amostragem mais completa, mas isso não impede que o modelo seja aplicado a outras instituições. Por fim, este trabalho tem a intenção apenas de ser um início. Estudos posteriores poderão confirmar a utilidade do modelo e realizar sua validação.

\section{Considerações finais}

Neste artigo foi desenvolvido um modelo matricial para classificação do desenho normativo de instituições reguladoras. Definimos desenho normativo como o conjunto de possibilidades de estruturação e de atuação de uma instituição 
que é delimitado pelas normas jurídicas que a criaram. Modelos matriciais já foram aplicados anteriormente, de forma genérica, ao estudo da regulação (Melo, 2001). Dois parâmetros — independência da instituição reguladora em relação ao poder central e transparência em relação à sociedade — foram estimados a partir da soma de pontos correspondentes a quatro variáveis (avaliadas nos textos normativos que criaram as instituições) para cada um dos parâmetros. Foram comparadas diferentes instituições reguladoras da atualidade e estas foram comparadas com instituições reguladoras da economia durante a república "populista": Instituto Nacional do Mate, Instituto Nacional do Sal, Instituto Nacional do Pinho, Instituto Brasileiro do Café e Instituto do Açúcar e do Álcool. A partir desse modelo, foram testadas quatro hipóteses principais e uma hipótese secundária.

O modelo confirmou quatro das hipóteses e rejeitou uma delas. Os testes revelam que as instituições reguladoras da atualidade são heterogêneas entre si quanto a seus desenhos normativos. São também heterogêneas entre si as agências dos setores de infra-estrutura (Anatel, Aneel, ANP, ANA, Antaq, ANTT) e aquelas dos setores "sociais" (ANS, Anvisa, Ancine). Ainda, as instituições reguladoras dos setores de infra-estrutura apresentam desenho normativo distinto em relação àquelas dos setores "sociais". As instituições reguladoras contemporâneas analisadas apresentam pontuações superiores à pontuação das autarquias econômicas do passado, tanto no parâmetro independência quanto no parâmetro transparência, porém a diferença é maior no segundo parâmetro do que no primeiro. Pelo menos uma instituição reguladora da atualidade, a Câmara Reguladora do Mercado de Medicamentos, apresenta pontuação inferior à pontuação das autarquias reguladoras da república "populista", tanto em independência quanto em transparência.

Foram ainda analisadas as implicações para a gestão pública e para futuros estudos e também as limitações do estudo.

\section{Referências bibliográficas}

ABRANCHES, S. Reforma regulatória: conceitos, experiências e recomendações. Revista do Serviço Público, v. 50, n. 2, p. 19-49, abr./jun. 1999.

BALDWIN, R.; CAVE, M. Understanding regulation: theory, strategy, and practice. Oxford: Oxford University Press, 1999.

BRASIL. Decreto-Lei n. 2.300, de 10 de junho de 1940. Cria o Instituto Nacional do Sal. Disponível em: <www.senado.gov.br>. Acesso em: 10 mar. 2004a.

RaP Rio de Janeiro 40(4):589-613, Jul./Ago. 2006 
Decreto-Lei n. 3.124, de 19 de março de 1941. Cria o Instituto Nacional do Pinho, e dá outras providências. Disponível em: <www.senado.gov.br>. Acesso em: 22 mar. 2004b.

Decreto-Lei n. 8.709, de 17 de janeiro de 1946. Reorganiza o Instituto Nacional do Mate e dá outras providências. Disponível em: <www.senado.gov.br>. Acesso em: 4 mar. $2004 c$.

Decreto-Lei n. 20.471, de 23 de janeiro de 1946. Aprova o Regulamento do Instituto Nacional do Pinho (INP). Disponível em: <www.senado.gov.br>. Acesso em: 23 mar. 2004d.

Decreto n. 29.118, de 10 de janeiro de 1951. Aprova o Regimento Interno do Instituto do Açúcar e do Álcool, reestrutura o quadro do seu pessoal, e dá outras providências. Disponível em: <www.senado.gov.br>. Acesso em: 11 mar. 2004e.

Lei n. 1.779, de 22 de dezembro de 1952. Cria o Instituto Brasileiro do Café, e dá outras providências. Disponível em: <www.senado.gov.br>. Acesso em: 18 abr. 2004f.

Lei n. 3.137, de 13 de maio de 1957. Denomina Instituto Brasileiro do Sal o Instituto Nacional do Sal, dando-lhe nova organização. Disponível em: <www.senado.gov.br>. Acesso em: 10 abr. 2004g.

Decreto-Lei n. 281, de 28 de fevereiro de 1967. Extingue o Instituto Nacional do Mate, e dá outras providências. Disponível em: <www.senado.gov.br>. Acesso em: 11 mar. 2004h.

. Lei n. 8.029, de 12 de abril de 1990. Dispõe sobre a extinção e dissolução de entidades da administração pública federal, e dá outras providências. Disponível em: <www.senado. gov.br>. Acesso em: 12 abr. $2004 i$.

Lei n. 9.427, de 26 de dezembro de 1996. Institui a Agência Nacional de Energia Elétrica - Aneel, disciplina o regime das concessões de serviços públicos de energia elétrica, e dá outras providências. Disponível em: <www.planalto.gov.br>. Acesso em: 18 abr. $2004 \mathrm{j}$.

Lei n. 9.472, de 16 de julho de 1997. Dispõe sobre a organização dos serviços de telecomunicações, a criação e funcionamento de um órgão regulador e outros aspectos institucionais, nos termos da Emenda Constitucional no 8, de 1995. Disponível em: $<$ www.planalto.gov.br>. Acesso em: 3 abr. 2004k.

Lei n. 9.478, de 6 de agosto de 1997. Dispõe sobre a política energética nacional, as atividades relativas ao monopólio do petróleo, institui o Conselho Nacional de Política Energética e a Agência Nacional do Petróleo, e dá outras providências. Disponível em: <www.planalto.gov.br>. Acesso em: 27 mar. 20041. 
Lei n. 9.782, de 26 de janeiro de 1999. Define o Sistema Nacional de Vigilância Sanitária, cria a Agência Nacional de Vigilância Sanitária, e dá outras providências. Disponível em: <www.planalto.gov.br>. Acesso em: 27 mar. 2004m.

. Lei n. 9.961, de 28 de janeiro de 2000. Cria a Agência Nacional de Saúde Suplementar - ANS e dá outras providências. Disponível em: <www.planalto.gov.br $>$. Acesso em: 22 mar. 2004n.

Lei n. 9.984, de 17 de julho de 2000. Dispõe sobre a criação da Agência Nacional de Águas - ANA, entidade federal de implementação da Política Nacional de Recursos Hídricos e de coordenação do Sistema Nacional de Gerenciamento de Recursos Hídricos, e dá outras providências. Disponível em: <www.planalto.gov.br>. Acesso em: 19 mar. 20040.

. Lei n. 10.233, de 5 de junho de 2001. Dispõe sobre a reestruturação dos transportes aquaviário e terrestre, cria o Conselho Nacional de Integração de Políticas de Transporte, a Agência Nacional de Transportes Terrestres, a Agência Nacional de Transportes Aquaviários e o Departamento Nacional de Infra-Estrutura de Transportes, e dá outras providências. Disponível em: <www.planalto.gov.br>. Acesso em: 16 mar. 2004p.

Lei n. 10.742, de 6 de outubro de 2003. Define normas de regulação para o setor farmacêutico, cria a Câmara de Regulação do Mercado de Medicamentos - CMED e altera a Lei $\mathrm{n}^{\circ}$ 6.360, de 23 de setembro de 1976, e dá outras providências. Disponível em: $<$ www.planalto.gov.br>. Acesso em: 8 abr. 2004q.

. Medida Provisória n. 2.228-1, de 6 de setembro de 2001. Estabelece princípios gerais da Política Nacional do Cinema, cria o Conselho Superior do Cinema e a Agência Nacional do Cinema - Ancine, e dá outras providências. Disponível em: <www.planalto.gov.br>. Acesso em: 17 abr. 2004r.

CÉSAR, N. da C. Autarquias econômicas. Revista do Serviço Público, p. 14-29, maio 1950.

DI PIETRO, M. S. Z. Direito administrativo. 14. ed. São Paulo: Atlas, 2002.

DISTEFANO III, J. J.; STUBBERUD, A. R.; WILLIAMS, I. J. Feedback and control systems (Schaum's Outlines). New York: McGraw-Hill, 1990.

LAFFONT, J. J. Externalities. In: EATWELL, J.; MILGATE, M.; NEWMAN, P. (Eds.). The new palgrave: a dictionary of economics. London: Macmillan Reference, 1998. v. 2, p. 263-265.

LEDYARD, J. O. Market failure. In: EATWELL, J.; MILGATE, M.; NEWMAN, P. (Eds.). The new palgrave: a dictionary of economics. London: Macmillan Reference, 1998. v. 3, p. 326-329.

MAJONE, G. Do Estado positivo ao Estado regulador: causas e consequiências de mudanças no modo de governança. Revista do Serviço Público, v. 50, n. 1, p. 5-36, jan./mar. 1999.

MELO, M. A. B. C. Política regulatória: uma revisão da literatura. Revista Brasileira de Informação Bibliográfica em Ciências Sociais, n. 50, p. 7-44, 2000.

RaP Rio de Janeiro 40(4):589-613, Jul./Ago. 2006 
PERLOFF, J. M.; CARLTON, D. Modern industrial organization. 2. ed. New York: Harper \& Collins, 1994.

VARIAN, H. R. Intermediate microeconomics: a modern approach. 6. ed. New York: Norton \& Company, 2003.

VISCUSI, W. K.; VERNON, J. M.; HARRINGTON JR., J. E. Economics of regulation and antitrust. 3. ed. Cambridge, Mass.: The MIT Press, 2000. 